\title{
Profiles, sources and potential exposures of parent, chlorinated and brominated polycyclic aromatic hydrocarbons in haze associated atmosphere
}

\author{
Rong Jin ${ }^{\mathrm{a}, \mathrm{b}}$, Guorui Liu ${ }^{\mathrm{a}, \mathrm{b}}$, Xiaoxu Jiang a,b ${ }^{\mathrm{a}}$, Yong Liang ${ }^{\mathrm{c}}$, Heidelore Fiedler ${ }^{\mathrm{d}}$, Lili Yang ${ }^{\mathrm{a}, \mathrm{b}}$, Qingqing Zhu ${ }^{\mathrm{a}, \mathrm{b}}$, \\ Yang Xu ${ }^{\mathrm{a}, \mathrm{b}}$, Lirong Gao ${ }^{\mathrm{a}, \mathrm{b}}$, Guijin Su ${ }^{\mathrm{a}, \mathrm{b}}$, Ke Xiao ${ }^{\mathrm{a}, \mathrm{b}}$, Minghui Zheng ${ }^{\mathrm{a}, \mathrm{c}, *}$ \\ a State Key Laboratory of Environmental Chemistry and Ecotoxicology, Research Center for Eco-Environmental Sciences, Chinese Academy of Sciences, Beijing 100085, China \\ ${ }^{\mathrm{b}}$ University of Chinese Academy of Sciences, Beijing 100049, China \\ c Institute of Environment and Health, Jianghan University, Wuhan 430056, China \\ ${ }^{\mathrm{d}}$ MTM Research Centre, School of Science and Technology, Örebro University, Sweden
}

\section{H I G H L I G H T S}

- Several congeners of $\mathrm{Cl}$, Br-PAHs in haze air were reported for the first time.

- $\mathrm{Cl}, \mathrm{Br}-\mathrm{PAH}$ levels in heating period were higher than that in non-heating period.

- Coal combustion contributes to the elevated levels of $\mathrm{Cl}$, Br-PAHs in heating period.

- Inhalation of PM was important exposure pathway of $\mathrm{Cl}, \mathrm{Br}-\mathrm{PAHs}$ in haze days.

\section{G R A P H I C A L A B S T R A C T}

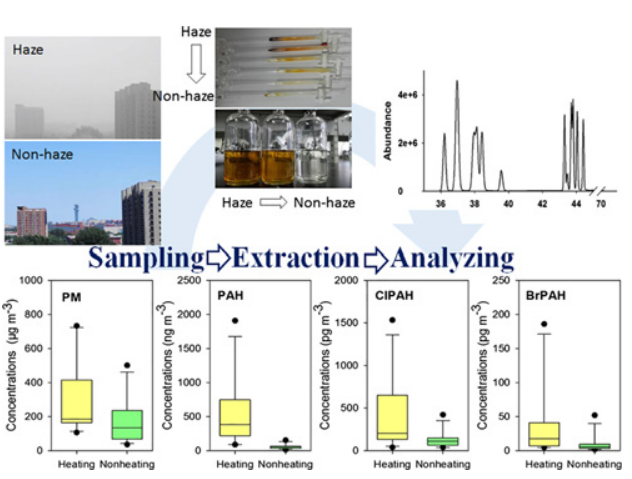

\begin{abstract}
A B S T R A C T
Profiles, sources and potential exposures of chlorinated and brominated polycyclic aromatic hydrocarbons ( $\mathrm{ClPAHs}$ and BrPAHs) in haze associated atmosphere remain unclear. Haze events happened frequently during heating period in Beijing provided a typical urban context to investigate the concentrations, profiles, sources and potential exposures of ClPAHs, BrPAHs and their non-halogenated parent compounds (PAHs) in air samples. Average concentrations of PAHs, ClPAHs and BrPAHs during heating periods (with more frequent haze events) were about 3-9 times higher than during non-heating periods. Concentrations of particulate matter (PM)-associated ClPAHs and BrPAHs were higher in heating period than in non-heating period, while for gas-associated ClPAHs and BrPAHs, this distinction was not significant. Congener patterns and congener profiles indicated that with increasing coal combustion during the heating period, concentrations of PAHs and ClPAHs in air were elevated in comparison to the non-heating period. Inhalation of PM-associated PAHs, ClPAHs and BrPAHs accounted for higher exposure than inhalation of gas phase and dermal contact of both gas phase and particulate phase. In this study we found that the particulate phase is the dominant exposure pathway of atmospheric PAHs, CIPAHs and BrPAHs during haze days, which is different from previous studies.
\end{abstract}

(c) 2017 Elsevier B.V. All rights reserved.

\footnotetext{
* Corresponding author at: State Key Laboratory of Environmental Chemistry and Ecotoxicology, Research Center for Eco-Environmental Sciences, Chinese Academy of Sciences, Beijing 100085, China.
}

E-mail address: zhengmh@rcees.ac.cn (M. Zheng). 


\section{Introduction}

Air pollution in developing countries has attracted increasing public attention as rapid urbanization and industrial development have taken place (Cao et al., 2016; Wang et al., 2014; Zheng et al., 2016). It has been found that air pollution can significantly increase lung cancer risk (Beelen et al., 2008; Pope et al., 2002). In 2010, premature mortality linked to air pollution in China was estimated to be 1357 thousand deaths (Lelieveld et al., 2015). A recent study reported that air pollution might even lead to the occurrence of fine particle matter in the human brain (Maher et al., 2016). Organic matter occurs in both gaseous and particulate fractions of the air, accounting for about $31-48 \%$ of fine particulate matter (PM) (Huang et al., 2014b). In spite of their trace occurrence in air, persistent organic pollutants (POPs) are potentially carcinogenic to human health (Van den Berg et al., 2006). POPs also pose a long-term adverse effect on human health because of their persistence and bioaccumulation.

Polycyclic aromatic hydrocarbons (PAHs), as ubiquitous organic pollutants in the atmosphere, have been of public concern for decades (Armstrong and Gibbs, 2009; Zhang et al., 2009). A number of studies have assessed atmospheric PAHs as to their sources, concentrations in air, distributions in particles of different sizes and lung cancer risk (Hong et al., 2016; Jia et al., 2011; Phoothiwut and Junyapoon, 2013; Zhang et al., 2009). PAH derivatives, such as chlorinated or brominated PAHs (ClPAHs or BrPAHs) have attracted attention only recently. The toxicological studies suggested that some ClPAHs and BrPAHs exhibited even higher carcinogenic and mutagenic toxicity than their non-halogenated parent PAHs (Horii et al., 2009; Ohura et al., 2007; Ohura et al., 2009). Typically, the toxicities of most 3-5 ring ClPAHs and BrPAHs are higher than 2-ring compounds (e.g., polychlorinated naphthalenes; PCN) (Noma et al., 2004; Ohura et al., 2007). PCNs have already been added to annexes A and C of the Stockholm Convention on Persistent Organic Pollutants. ClPAHs and BrPAHs also tend to be bound to the Aryl hydrocarbon receptor (AhR), causing them to display a similar toxicity to that of notorious polychlorinated dibenzo-p-dioxins and dibenzofurans (PCDD/Fs). In some specific environmental contexts, ClPAHs contribute much more to the total toxic equivalents (TEQs) than PCDD/Fs (Ma et al., 2009). It was estimated that the toxicity of exposure to CIPAHs, based on their AhR activities, was approximately 30-50 times higher than for dioxins in urban air in Japan (Ohura et al., 2007). To date, studies of the occurrence, sources and health risks of CIPAHs and BrPAHs in air samples are clearly insufficient, compared with their parent PAH compounds. Although a few case studies reported the concentrations, profiles, size distributions and health risks of PM-associated ClPAHs in urban air (Kakimoto et al., 2016; Kitazawa et al., 2006; Ma et al., 2013; Ohura et al., 2016; Ohura et al., 2005; Ohura et al., 2009; Sun et al., 2015; Wang et al., 2012), those for gas-associated ClPAHs are still very limited. No study has yet described the occurrence, sources and health risks of BrPAHs in gaseous and particulate air fractions.

In winter, large amount of coals are combusted to give warm in north China, and this season is normally called heating period. During the heating period, haze events happened frequently. A comparison between heating and non-heating period in Harbin, China suggested that the atmospheric PAH concentrations in heating period were approximately 3-17 fold of those in non-heating period (Ma et al., 2010). Coal combustion was suggested to be the major factors for the elevated PAH concentrations in heating period (Ma et al., 2010). But, whether the coal combustion in heating period would contribute to atmospheric ClPAHs and BrPAHs or not remains unclear.

Haze episodes in Beijing have attracted wide public concern in recent years (Fig. S1) (Huang et al., 2014a; Sun et al., 2016). There were two 'red' haze alarms (the highest grade of alarm for haze pollutions, predicting serious PM pollution for more than three days) and one 'orange' haze alarm (predicting serious PM pollution for three days) between August 2015 and March 2016 in Beijing. The most severe haze episode occurred between November 26 and December 1, 2015 with an hourly maximum $\mathrm{PM}_{2.5}$ concentration of up to $626 \mu \mathrm{g} \mathrm{m}^{-3}$. During these haze events, normal activities of workers and students were severely disrupted. For example, all teaching activities in schools were stopped during the 'red' alarm in Beijing.

The compositions, sources and health risks of haze pollution in Beijing have attracted great attention because of the seriousness of these haze events. Although some studies have addressed composition, sources and health risks of PM in haze episodes (Andersson et al., 2015; Betha et al., 2014; Liu et al., 2014), the occurrences, sources and associated health risks of trace CIPAHs, BrPAHs in particulate and gas fractions have never been studied, due to the requirement of high-volume air samplers and the difficulties in achieving accurate analytical results for ClPAHs and BrPAHs. Previous studies indicate that Beijing has one of the highest atmospheric PAH concentrations in several investigated cities in Asia (Hong et al., 2016; Zhang et al., 2016). Likewise, PM-associated ClPAHs had highest concentrations in air samples from Beijing, compared with the investigated other several Asian cities (Kakimoto et al., 2014). Therefore, it is vital to clarify the levels and sources of ClPAHs, BrPAHs and their parent compounds in Beijing, using haze events from August 2015 to March 2016 as a case study. An evaluation of risks of ClPAHs, BrPAHs and PAHs in haze also is critical to protect the health of Beijing's population.

The accurate quantification of congener specific ClPAHs and BrPAHs remains a challenge. In this study, isotopic dilution high-resolution gas chromatography combined with high-resolution mass spectrometry (HRGC/HRMS) was used for simultaneously analysing 19 CIPAH and $19 \mathrm{BrPAH}$ (3-5 ring) congeners in air samples. Some specific congeners were analysed for the first time in this study. The sources and the exposure risks of these pollutants in haze are discussed. To the best of our knowledge, this is the first study to simultaneously report CIPAHs, BrPAHs and their parent compounds, in both gaseous and particulate fractions during serious haze in Beijing. It provides important data on the adverse effects of trace carcinogenic organic contaminations in haze on human health.

\section{Materials and methods}

\subsection{Abbreviations for the congeners}

The 19 PAH congeners determined in this study were listed as follows: naphthalenes (Nap), 2-methynaphthalenes (2-MNap), acenaphthylene (Any), Acenaphthene (Ana), fluorene (Fle), phenanthrene (Phe), anthracene (Ant), fluoranthene (Flu), pyrene (Pyr), benzo( $a$ )anthracene $(\mathrm{BaA})$, chrysene $(\mathrm{Chr})$, benzo(b)fluoranthene $(\mathrm{BbF})$, benzo $(k)$ fluoranthene $(\mathrm{BkF})$, benzo(e)pyrene (BeP), benzo( $a$ )pyrene $(\mathrm{BaP})$, perylene (Per), indeno(1,2,3-cd)pyrene (IcdP), dibenz( $a h)$ anthracene (DahA), benzo(ghi)perylene (BghiP). The abbreviations of $19 \mathrm{ClPAH}$ and $19 \mathrm{BrPAH}$ congeners were also derived from their PAH skeletons. For example, 9-ClPhe represents the 9chlorophenanthrene, and $1,2-\mathrm{Br}_{2} \mathrm{Any}$ represents the 1,2dibromoacenaphthylene. The only exception was 2-BrTriph, which represented the 2-bromotriphenylene. Details about the abbreviations of $\mathrm{ClPAH}$ and BrPAH congeners were listed in Table S1.

\subsection{Sampling method}

Air samples were collected from August 2015 to March 2016 in Beijing from the rooftop of a building $\left(116^{\circ} 12^{\prime} 28^{\prime \prime} \mathrm{E}, 40^{\circ} 00 \mathrm{E}, 4 \mathrm{~N}\right)$, around $20 \mathrm{~m}$ above ground. Sampling period covered both heating period (from Nov. 7, 2015 to Mar. 15, 2016: including the heating test time) and nonheating period in Beijing. This sampling station is an ecological and environmental monitoring station in Beijing. There are research institutes, residential buildings and local streets around the sampling site, typical of an urban setting. Samples were collected using high-volume samplers (Echo Hi-Vol, Tecora Co., France). The gaseous phase PAHs and halogenated PAHs (HPAHs) were adsorbed onto polyurethane foam (PUF; 
Tisch Environmental, USA) having a $63 \mathrm{~mm}$-diameter and 72-mm length. TSP samples were trapped on cleaned quartz fiber filters (QFFs) (102 $\mathrm{mm}$ in diameter). After sampling, the samples were wrapped in aluminium foil, sealed in plastic bags and stored at -18 ${ }^{\circ} \mathrm{C}$ until analysis.

\subsection{Analytical method}

For identification and analysis of ClPAHs and BrPAHs, isotopic dilution high-resolution gas chromatography combined with high-resolution mass spectrometry (HRGC/HRMS; Thermal Fisher Scientific, USA) was used for simultaneously analysing $19 \mathrm{ClPAH}$ and $19 \mathrm{BrPAH}$ (3-5 ring) compounds in air samples. More specifically, the air samples were spiked with five ${ }^{13} \mathrm{C}$-labelled and one d-labelled internal standards $\left({ }^{13} \mathrm{C}_{6}-9-\mathrm{ClPhe},{ }^{13} \mathrm{C}_{6}-2\right.$-ClAnt, ${ }^{13} \mathrm{C}_{6}-1-\mathrm{ClPyr},{ }^{13} \mathrm{C}_{6}-7-\mathrm{ClBaA},{ }^{13} \mathrm{C}_{6}-7-\mathrm{BrBaA}$ and $d_{9}-9$-BrPhe) for identification and quantification of ClPAHs and BrPAHs, and $d$-labelled internal standards ( $\mathrm{d}_{8}$-Nap, $\mathrm{d}_{10}-2-\mathrm{MNap}, \mathrm{d}_{8^{-}}$ Any, $\mathrm{d}_{10}-$ Phe, $\mathrm{d}_{10}-$ Fle, $\mathrm{d}_{12}-\mathrm{BaA}, \mathrm{d}_{12}-\mathrm{Chr}, \mathrm{d}_{12}-\mathrm{BbF}, \mathrm{d}_{12}-\mathrm{BkF}, \mathrm{d}_{12}-\mathrm{BaP}, \mathrm{d}_{12^{-}}$ Per, $d_{12}$-IcdP, $d_{14}$-DahA, $d_{12}$-BghiP) for PAHs before extraction. Extraction was done via accelerating solvent extraction (ASE) using a 1:1 mixture of hexane and dichloromethane. After rotary evaporation, the concentrated extract was passed through a silica column, which was eluted by a 4:1 mixture of hexane and dichloromethane, and a convertible active carbon column which was eluted by toluene. The extract was then concentrated to about $50 \mu \mathrm{L}$ using nitrogen. ${ }^{13} \mathrm{C}$-labelled $\left({ }^{13} \mathrm{C}-7,12\right.$ $\mathrm{Cl}_{2} \mathrm{BaA}$ ) for ClPAHs and BrPAHs and d-labelled ( $\mathrm{d}_{10^{-}}$-Ana, $\mathrm{d}_{10^{-}} \mathrm{Pyr}, \mathrm{d}_{12^{-}}$ $\mathrm{BeP}$ ) injection standards for PAHs were added before instrumental analysis, with the aim of evaluating the analytical recoveries of labelled internal standards.

Separation was performed on a HRGC column (DB-5 ms column, $60 \mathrm{~m} \times 0.25 \mu \mathrm{m} \times 0.25 \mathrm{~mm}$; Agilent Technology, USA) under splitless mode. The initial temperature was $50{ }^{\circ} \mathrm{C}$, increased with a rate of 25 ${ }^{\circ} \mathrm{C} \mathrm{min}-1$ to $175^{\circ} \mathrm{C}$, then $5{ }^{\circ} \mathrm{C} \mathrm{min}^{-1}$ to $200{ }^{\circ} \mathrm{C}$ (over $28 \mathrm{~min}$ ), then 8 ${ }^{\circ} \mathrm{C} \min ^{-1}$ to $300{ }^{\circ} \mathrm{C}$ (over $10 \mathrm{~min}$ ) and then $1{ }^{\circ} \mathrm{C} \mathrm{min}-1$ to $305{ }^{\circ} \mathrm{C}$ (over $5 \mathrm{~min}$ ). Selected ion monitoring (SIM) mode was used to acquire data. Detection was achieved at a resolution above 10,000.

PAHs were identified and quantified on a gas chromatograph (6890; Agilent Technology, USA) coupled to a mass spectrometer (5973; Agilent Technology, USA). The SIM ions and the analytical methods were in accordance with US EPA Method 429.

Recoveries were evaluated to be $39-78 \%$, 43-83\%, 44-80\%, 41-93\%, 70-99\% and 62-98\% for ${ }^{13} \mathrm{C}_{6}-9-\mathrm{ClPhe},{ }^{13} \mathrm{C}_{6}-2$-ClAnt, d $\mathrm{d}_{9}-9-\mathrm{BrPhe},{ }^{13} \mathrm{C}_{6}$ 1-ClPyr, ${ }^{13} \mathrm{C}_{6}-7-\mathrm{ClBaA}$, and ${ }^{13} \mathrm{C}_{6}-7-\mathrm{BrBaA}$ respectively. For PAHs, the recoveries were in the range of $61-116 \%$. Blank determination was done for each batch of the samples. The concentrations of ClPAHs and BrPAHs in the blanks were lower than $5 \%$ of those in samples.

\subsection{Exposure models}

The exposures of PAHs, ClPAHs and BrPAHs related to air inhalation and dermal contact were estimated according to models described in previous publications (Sun et al., 2015; Xia et al., 2013). These models were developed during the International Commission on Radiological Protection, and used to calculate the daily intake of compounds imbibed via inhalation and dermal contact (International Commission on Radiological Protection, 1994).

The benzo[a]pyrene equivalent $\left(\mathrm{BaP}_{\mathrm{eq}}\right)$ concentrations of PAHs, CIPAHs and BrPAHs were calculated using Eq. (1):

$\mathrm{BaP}_{e q}=\sum\left[C_{i}\right] \times R P F_{B a P}$

$R P F_{B a P}$ were the relative potency factors of PAHs, ClPAHs and BrPAHs relative to benzo[a]pyrene (Table $S 2$ ). $C_{i}$ were the concentrations of PAHs, ClPAHs and BrPAHs. The population of Beijing was divided into three age groups: children (1-11 years old), adolescents (12-17 years old) and adults (18-70 years old). Daily intake ( $\mathrm{ng} \mathrm{d}^{-1}$ or $\mathrm{pg} \mathrm{d}^{-1}$ )
(DI) of PAHs and ClPAHs and BrPAHs through inhalation ( $\mathrm{DI}_{\mathrm{ig}}$ for gaseous phase and $\mathrm{DI}_{\mathrm{ip}}$ for particulate phase) and dermal contact $\left(\mathrm{DI}_{\mathrm{dg}}\right.$ for gaseous phase and $\mathrm{DI}_{\mathrm{dp}}$ for particulate phase) were calculated using Eqs. (2)-(5), where $C_{\mathrm{ig}}$ and $\mathrm{C}_{\mathrm{ip}}$ are the concentrations of gas-associated and particle-associated PAHs $\left(\mathrm{ng} \mathrm{m}^{-3}\right)$ or ClPAHs and BrPAH $\left(\mathrm{pg} \mathrm{m}^{-3}\right)$, respectively; IR is the inhalation rate $\left(\mathrm{m}^{3} \mathrm{~d}^{-1}\right)$; SA is the exposure skin surface area $\left(\mathrm{cm}^{2}\right) ; f_{a}$ is the exposure fractions for the skin surface area; and $\mathrm{k}_{\mathrm{p} \_\mathrm{g}}$ and $\mathrm{k}_{\mathrm{p \_ d}}$ are the transdermal permeability coefficients of gaseous compounds and particulate compounds, respectively (Table S3).

$$
\begin{aligned}
& \mathrm{DI}_{\mathrm{ig}}=\sum\left(\mathrm{C}_{\mathrm{ig}} \times \mathrm{RPF}_{\mathrm{BaP}}\right) \times \mathrm{IR} \\
& \mathrm{DI}_{\mathrm{ip}}=\sum\left(\mathrm{C}_{\mathrm{ip}} \times \mathrm{RPF}_{\mathrm{BaP}}\right) \times \mathrm{IR} \\
& \mathrm{DI}_{\mathrm{dg}}=\sum\left(\mathrm{C}_{\mathrm{ig}} \times \mathrm{RPF}_{\mathrm{BaP}}\right) \times \mathrm{k}_{\mathrm{p} \_\mathrm{g}} \times \mathrm{SA} \times f_{a} \\
& \mathrm{DI}_{\mathrm{dp}}=\sum\left(\mathrm{C}_{\mathrm{ip}} \times \mathrm{RPF}_{\mathrm{BaP}}\right) \times \mathrm{k}_{\mathrm{p} \_\mathrm{d}} \times \mathrm{SA} \times f_{a}
\end{aligned}
$$

The uncertainty and sensitivity analysis was carried out with a Monte Carlo simulation using the software Crystal Ball 11.1 (Oracle Corp., Redwood Shores, CA, USA). The simulation selects a value of each variable according to their distributions, and runs for 10,000 iterations to generate the 2.5 th and 97.5 th percentiles at a $95 \%$ confidence interval; it also generates 50th percentiles for the median values for all calculations. The $t$-test, PCA and the Pearson's correlations were conducted using SPSS 20 (IBM Corp., Armonk, NY, USA).

\section{Results and discussion}

\subsection{Concentrations and gas-particle distributions of PAHs, CIPAHs and BrPAHs}

Haze events are normally more frequent in cool seasons, when heating takes place by mainly using coal combustion to give warm, than in non-heating period in Beijing. Concentrations of the PM, $\sum_{19}$ PAHs, $\sum_{19}$ ClPAHs and $\sum_{19}$ BrPAHs in the air samples of Beijing are shown in Fig. 1 and Table 1. The concentrations of PM varied from $36.0 \mu \mathrm{g} \mathrm{m} \mathrm{m}^{-3}$ to $732.5 \mu \mathrm{g} \mathrm{m} \mathrm{m}^{-3}$ (with an average of $242.1 \mu \mathrm{g} \pm 190.3$ $\left.\mu \mathrm{g} \mathrm{m}^{-3}\right)$. The highest concentration $\left(732.5 \mu \mathrm{g} \mathrm{m}^{-3}\right)$ of PM occurred between Nov. 30, 2015 and Dec. 1, 2015. Average PM concentrations were obviously higher in the heating period $\left(312.9 \pm 218.525 \mu \mathrm{g} \mathrm{m}{ }^{-3}\right)$ than in the non-heating period $\left(177.3 \mu \mathrm{g} \mathrm{m}^{-3} \pm 139.4 \mu \mathrm{g} \mathrm{m}^{-3}\right)$, suggesting that PM contamination is more serious in heating period.

The average concentrations (gases phase + particulate phase) of $\sum_{19}$ PAHs, $\sum_{19} \mathrm{ClPAHs}$ and $\sum_{19} \mathrm{BrPAHs}$ in the heating period were $549.3 \pm 506.1 \mathrm{ng} \mathrm{m}^{-3}$ (range: 88.4-1907.3 $\mathrm{ng} \mathrm{m}^{-3}$ ), $401.4 \pm$ $431.9 \mathrm{pg} \mathrm{m}^{-3}$ (range: $39.3 \mathrm{pg} \mathrm{m}^{-3}-1532.9 \mathrm{pg} \mathrm{m}^{-3}$ ) and $40.0 \pm$ $57.3 \mathrm{pg} \mathrm{m}^{-3}$ (range: $4.6 \mathrm{pg} \mathrm{m}^{-3}-185.8 \mathrm{pg} \mathrm{m}^{-3}$ ), respectively. These values were clearly higher than averages for the non-heating period ( $\sum_{19}$ PAHs: $59.1 \pm 35.2 \mathrm{ng} \mathrm{m}^{-3}, \sum_{19}$ ClPAHs: $128.8 \pm 102.6 \mathrm{pg} \mathrm{m}^{-3}$, and $\sum_{19}$ BrPAHs: $9.5 \mathrm{pg} \mathrm{m}^{-3} \pm 13.8 \mathrm{pg} \mathrm{m}^{-3}$ ). Highest concentrations of PAHs, ClPAHs and BrPAHs were recorded between Nov. 30, 2015 and Dec. 1, 2015, coincident with highest PM concentrations. Significant correlations of PM with PAH concentrations $(r=0.75, p<0.01)$, CIPAH concentrations $(r=0.83, p<0.01)$ and $\mathrm{BrPAH}$ concentrations $(r=0.62$, $p<0.01$ ) indicate that sources of PAHs, ClPAHs and BrPAHs likely contribute to haze events in Beijing.

PAH concentrations in the non-heating period were comparable to previous studies conducted in Guangzhou, China (Gao et al., 2015), Vietnam (Hong et al., 2016) and India (Hong et al., 2016); they were higher than in Japan (Hong et al., 2016; Kitazawa et al., 2006), South Korea (Hong et al., 2016) and Italy (Sangiorgi et al., 2014), but lower than in urban areas of Taiyuan (Xia et al., 2013), Shanxi and Shandong in northern China (Zhang et al., 2016). PAH concentrations during the heating period of this study were noticeably higher than average $\mathrm{PAH}$ 


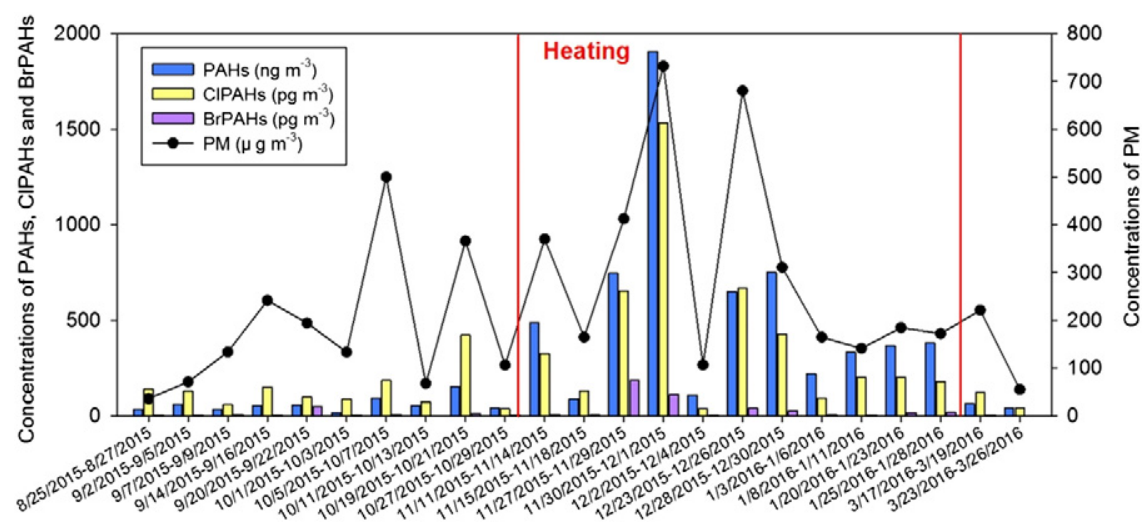

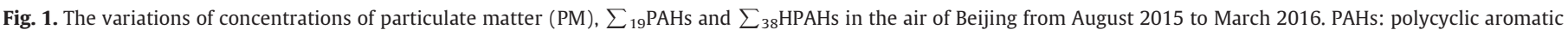
hydrocarbons, HPAHs: halogenated PAHs.

concentrations in industrial regions, which were considered to have one of the highest PAH concentrations ever reported (Aydin et al., 2014; Paloluoğlu et al., 2015). The concentrations of CIPAHs in air samples in the non-heating period were comparable with results from Japan (with an average of $110 \mathrm{pg} \mathrm{m}^{-3}$ ), but concentrations in the heating period were significantly higher than in Japan (Ohura et al., 2008). There was no available data for comparisons of BrPAHs to differentiate between the gaseous and particulate fractions. The average concentration of PM-associated BrPAHs in urban air samples from Japan in the years 2004 and 2005 was $8.6 \mathrm{pg} \mathrm{m}^{-3}$, which is lower than any value found during the whole sampling period of this study (Ohura et al., 2009).

The average concentrations of PAHs, ClPAHs and BrPAHs reported in this study were compared with other persistent organic pollutants from previous studies (Table S4). The concentrations of ClPAHs converted to AhR toxicity (Table S5) were similar to those of 2,3,7,8-PCDD/Fs. The concentrations of BrPAHs converted to AhR toxicity were similar to dlPCBs reported previously. This indicates that CIPAHs and BrPAHs should be included in human health risk assessments.

As for the gas-phase versus particle distributions, the concentrations of PM-associated PAHs, ClPAHs and BrPAHs were $127.6 \mathrm{ng} \mathrm{m}^{-3} \pm$ $193.0 \mathrm{ng} \mathrm{m}^{-3}, 92.6 \mathrm{pg} \mathrm{m}^{-3} \pm 71.4 \mathrm{pg} \mathrm{m}^{-3}$ and $18.3 \mathrm{pg} \mathrm{m}^{-3} \pm$ $39.8 \mathrm{pg} \mathrm{m}^{-3}$, respectively, accounting for about $43.5 \%, 35.5 \%$ and $75.9 \%$ of their total atmospheric concentrations (Table 1, Fig. 2). The fractions of PM-associated PAHs and ClPAHs were higher than most previous studies investigating the gas-particle partitioning of PAHs and ClPAHs in the atmosphere (Gregoris et al., 2014; Ohura et al., 2008; Park et al., 2001).

Concentrations of PM-associated PAHs, ClPAHs and BrPAHs as well as gas-associated PAHs during the heating period were significantly higher than during the non-heating period ( $t$-test, $p<0.05$ ). However, for gas phase ClPAHs and BrPAHs, this distinction was not significant ( $t$-tests with $p=0.780>0.05$ and $p=0.788>0.05$, respectively). The higher concentrations of PM-associated CIPAHs and BrPAHs during the heating period suggested that concentrations of PM-associated or gasassociated ClPAHs and BrPAHs could be affected by different factors.

\subsection{Profiles of atmospheric PAHs, ClPAHs and BrPAHs}

Analysing the profiles of PAHs, ClPAHs and BrPAHs was useful for tracing their sources. Concentrations of various PAHs, ClPAHs and BrPAHs encountered during our sampling period are given in Table S6. Average concentrations of individual PAHs ranged from $1.5 \mathrm{ng} \mathrm{m}^{-3}$ for Ana to $64.5 \mathrm{ng} \mathrm{m}^{-3}$ for Phe. Average concentrations of ClPAH congeners ranged from $0.05 \mathrm{pg} \mathrm{m}^{-3}$ for $1,5,9,10-\mathrm{Cl}_{4}$ Ant to $62.9 \mathrm{pg} \mathrm{m}^{-3}$ for 9$\mathrm{ClPhe} / 2-\mathrm{ClPhe}$, while average concentrations of $\mathrm{BrPAH}$ congeners ranged from $0.04 \mathrm{pg} \mathrm{m}^{-3}$ for $1,2-\mathrm{Br}_{2} \mathrm{Any}$ to $5.80 \mathrm{pg} \mathrm{m}^{-3}$ for $1,8-$ $\mathrm{Br}_{2} \mathrm{Ant} / 1,5-\mathrm{Br}_{2} \mathrm{Ant}$. Concentrations of some ClPAH congeners, such as 3-ClPhe, 2-ClPhe, 1-ClAnt, 2,7- $\mathrm{Cl}_{2} \mathrm{Fle}, 1,4-\mathrm{Cl}_{2} \mathrm{Ant}, 1,5,9,10-\mathrm{Cl}_{4} \mathrm{Ant}$, and most of the BrPAH congeners, including 5-BrAna, 1,2- $\mathrm{Br}_{2} \mathrm{Any}$, 3-BrPhe, etc., are reported here for the first time. These congener concentrations and profiles could provide much abundant information for understanding the potential risks of ClPAHs and BrPAHs in the haze associated air.

The concentrations of several PAH congeners varied markedly between heating and non-heating periods (Fig. 3). Some gas-phase compounds, such as Phe, Flu and Pyr, had higher fractions in the nonheating period than in heating period. In contrast, gas phase Fle had higher fractions in the heating period. For PM-associated PAHs, Flu, Pyr, BaA and Chr had higher fractions in the heating period, while IcdP and BghiP had higher fractions in the non-heating period. The different congener profiles suggest that the sources for atmospheric PAHs were different in different periods. Congener distributions for CIPAHs in the heating period were obviously different from the non-heating period. For gas-associated ClPAHs, 9-ClPhe/2-ClPhe, 3-ClPhe, 2-ClAnt and 3ClFlu, were the major compounds reported during the heating period, while in the non-heating period, these were 9-ClPhe/2-ClPhe, 3-ClPhe, 1,4- $\mathrm{Cl}_{2} \mathrm{Ant}, 9,10-\mathrm{Cl}_{2} \mathrm{Phe}, 3-\mathrm{ClFlu}$ and 1 -ClPyr. In the PM, 6-ClBaP was

Table 1

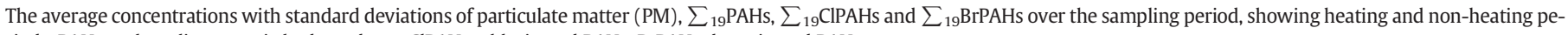
riods. PAHs: polycyclic aromatic hydrocarbons, CIPAHs: chlorinated PAHs, BrPAHs: brominated PAHs.

\begin{tabular}{|c|c|c|c|c|c|c|}
\hline & & Samples & $\mathrm{PM}\left(\mu \mathrm{g} \mathrm{m}^{-3}\right)$ & PAHs (ng m ${ }^{-3}$ ) & ClPAHs $\left(\mathrm{pg} \mathrm{m}^{-3}\right)$ & BrPAHs $\left(\mathrm{pg} \mathrm{m}^{-3}\right)$ \\
\hline \multirow[t]{3}{*}{ Whole sampling time } & Total & 23 & $242.1 \pm 190.3$ & $293.6 \pm 423.9$ & $260.6 \pm 330.4$ & $24.1 \pm 42.8$ \\
\hline & Gaseous phase & & & $166.1 \pm 250.1$ & $166.6 \pm 298.4$ & $5.8 \pm 8.7$ \\
\hline & Particulate phase & & & $127.6 \pm 193.0$ & $92.6 \pm 71.4$ & $18.3 \pm 39.8$ \\
\hline \multirow[t]{3}{*}{ Heating period } & Total & 11 & $312.9 \pm 218.5$ & $549.3 \pm 506.1$ & $401.4 \pm 431.9$ & $40.0 \pm 57.3$ \\
\hline & Gaseous phase & & & $299.9 \pm 314.8$ & $89.0 \pm 68.3$ & $5.3 \pm 4.9$ \\
\hline & Particulate phase & & & $249.4 \pm 224.7$ & $312.4 \pm 387.4$ & $34.7 \pm 53.9$ \\
\hline \multirow[t]{3}{*}{ Non-heating period } & Total & 12 & $177.3 \pm 139.4$ & $59.1 \pm 35.2$ & $128.8 \pm 102.6$ & $9.5 \pm 13.8$ \\
\hline & Gaseous phase & & & $43.3 \pm 25.2$ & $95.8 \pm 76.9$ & $6.3 \pm 11.4$ \\
\hline & Particulate phase & & & $15.8 \pm 11.4$ & $33.0 \pm 31.2$ & $3.2 \pm 3.2$ \\
\hline
\end{tabular}



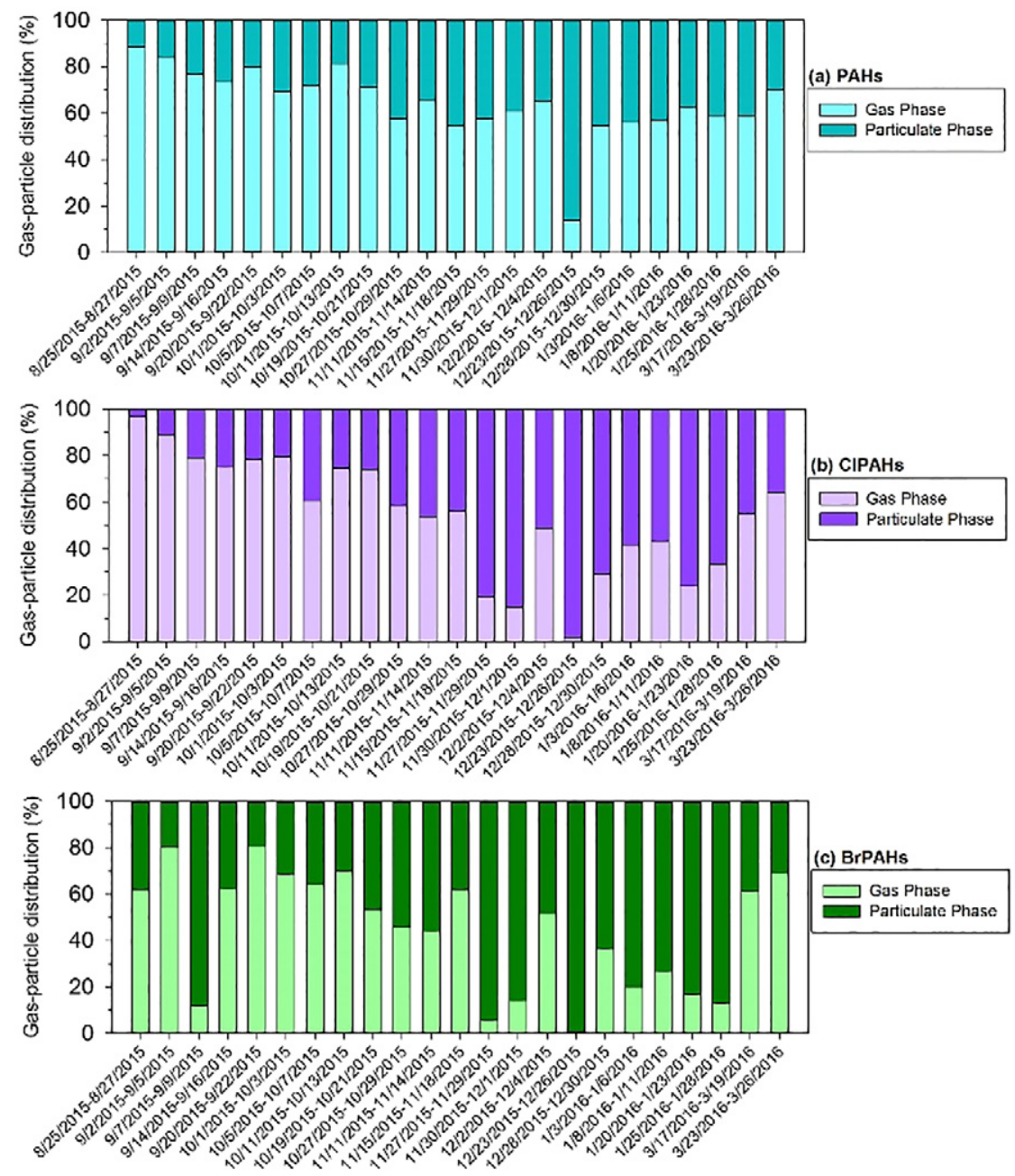

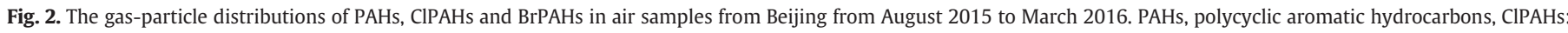
chlorinated PAHs, BrPAHs: brominated PAHs.

the dominant congener in the non-heating period, followed by 3-ClFlu, 1-ClPyr and 9-ClPhe/2-ClPhe. This profile is consistent with previous studies conducted under non-haze conditions (normal days) (Kitazawa et al., 2006; Ma et al., 2013). During the heating period, 3ClFlu and 1-ClPyr had higher fractions in the PM than 6-ClBaP. The different ClPAHs distributions for heating and non-heating sampling periods indicated that their dominant sources were different in each period. 3-BrPhe, 9-BrPhe, 2-BrPhe, 1-BrAnt and 1,8- $\mathrm{Br}_{2} \mathrm{Ant} / 1,5-\mathrm{Br}_{2} \mathrm{Ant}$ were the major BrPAHs in the gaseous phase, while 3-BrFlu, 1,8$\mathrm{Br}_{2} \mathrm{Ant} / 1,5-\mathrm{Br}_{2} \mathrm{Ant}$ and 1-BrPyr were the major BrPAHs in the PM. There was no obvious difference in BrPAHs distributions between heating and non-heating periods.

\subsection{Sources of PAHs, CIPAHs and BrPAHs in haze associated atmosphere}

Diagnostic ratios of PAHs can be used to apportion sources of PAHs in haze. Anthropogenic activities, such as coal burning, waste incineration and use of automobiles, have been identified as important sources of atmospheric PAHs. In this study, an important distinction in anthropogenic activities occurs between heating and non-heating periods, related to the burning of coal for heating purposes. Coal consumption for each province in China in 2014 is shown in Fig. S2. The provinces that consumed the most coal are all located around Beijing. Ratios of Flu/(Flu + Pyr $), A n t /($ Ant + Phe $), \mathrm{BaA} /(\mathrm{BaA}+\mathrm{Chr})$ were calculated to explore the sources of PAHs in the atmosphere in non-heating and heating periods in Beijing (Fig. S3). Ratios of Ant/(Ant + Phe) were usually $>0.1$ in the heating period, while in non-heating period, they were mostly $<0.1$. Ratios of $\mathrm{BaA} /(\mathrm{BaA}+\mathrm{Chr})$ were almost always $>0.35$ in heating period, and lower than 0.35 in non-heating period. These values indicate the dominance of combustion sources during heating periods, as opposed to a significant contribution from both petroleum emission and combustion sources during non-heating periods. In addition to calculating the diagnostic ratios of several specific congeners, a principal component analysis (PCA) was carried out to apportion sources (Table S7). Compositional analysis of factors extracted in this study indicate that combustion sources, such as the coal burning explain $89 \%$ of the total variance in the heating period. In contrast, petroleum sources, including vehicle emission explain $78 \%$ of the total variance in the nonheating period.

A Pearson's correlation analysis indicates that significant correlations were found between the PM-associated ClPAHs or BrPAHs and PM-associated parent PAHs. In contrast, correlations between most gas-associated ClPAHs or BrPAHs and gas-associated parent PAHs were not significant (Table S8). This suggests that secondary formation of ClPAHs or BrPAHs through chlorination or bromination of parent PAHs is an important pathway for PM-associated ClPAHs and BrPAHs formation, but it is not for gas-associated CIPAHs and BrPAHs. Ratios of selected CIPAHs, normalized to 1-ClPyr and 3-ClFlu, in both gaseous phase and particulate phase are shown in Table 2; these ratios could be used to identifying CIPAH sources. The ratios of PM-associated ClPAHs varied between heating and non-heating periods, while they were similar for gas-associated congeners for both periods. The ratios 

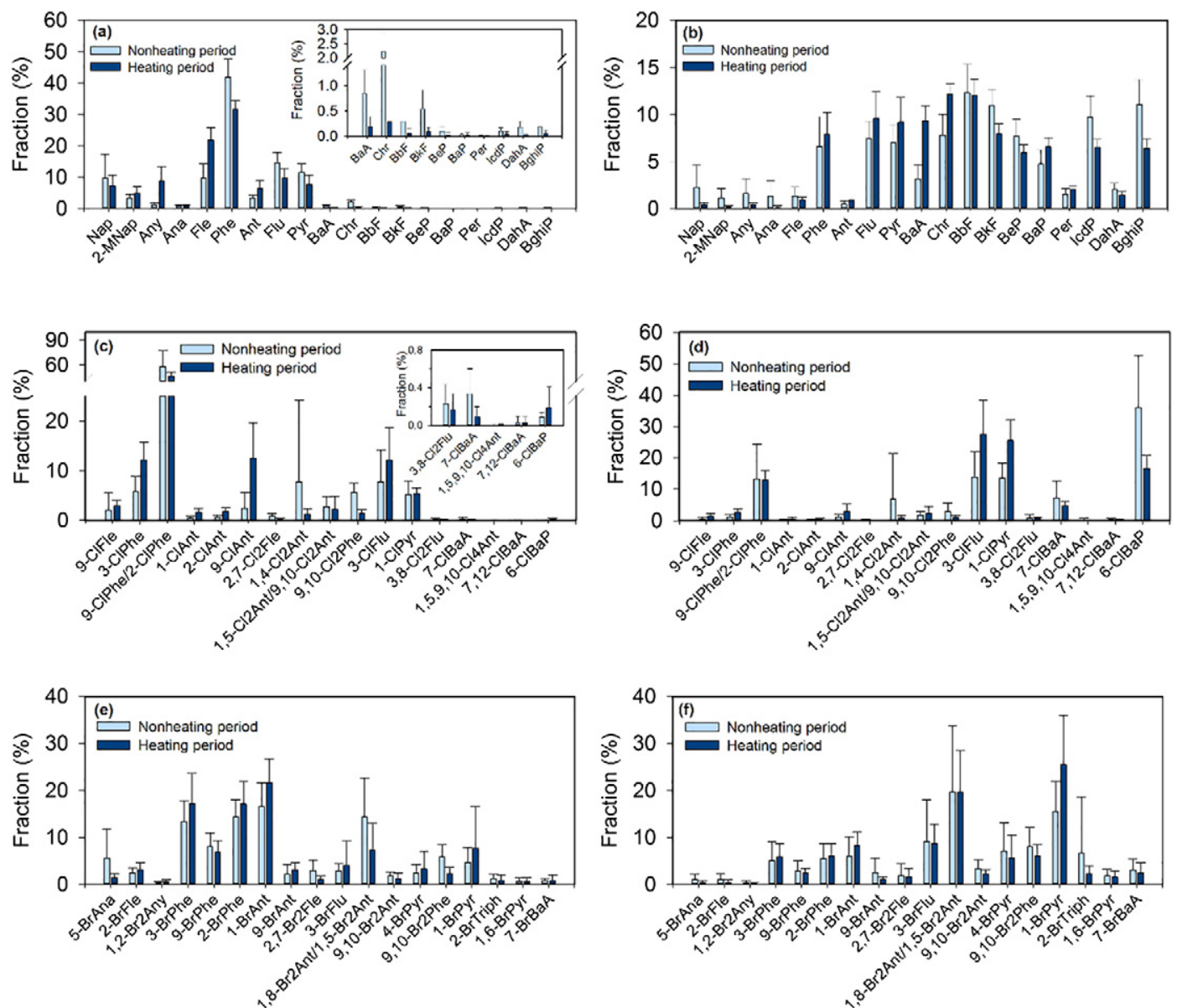

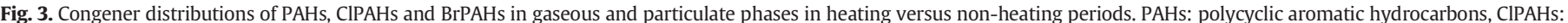

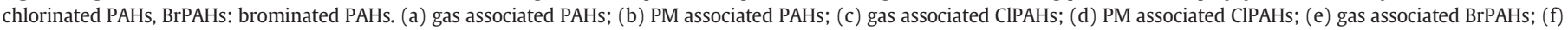
PM associated BrPAHs.

during the non-heating period were similar to ratios in PM from urban air in Japan, as well as ratios for $\mathrm{PM}_{10}$ and $\mathrm{PM}_{2.5}$ in suburban air from Shanghai, and fly-ash from waste incinerators. These observations suggest that the sources for CIPAHs in the non-heating period in Beijing are similar to other cities. Flu and Pyr are considered to be indicators for PAHs derived from coal burning (Harrison et al., 1996). Their chlorinated derivatives, 3-ClFlu and 1-ClPy, are likely formed through chlorination of Flu and Pyr during coal burning. Therefore, 3-ClFlu and 1-ClPy are proposed here as potential indicators for coal burning. The fractions of Flu, Pyr, 3-ClFlu and 1-ClPy were clearly elevated during the heating period. This further verifies that coal burning is a significant contributor to atmospheric PAHs and CIPAHs during the heating period. As regards to BrPAHs, even less studies have reported their profiles in the atmosphere. In previous studies, sources that emitted chlorine-substituted POPs also emitted their brominate-substituted analogs (Li et al., 2015; Wang et al., 2016). Therefore, the sources that emitted CIPAHs could also be regard as potential sources of BrPAHs. However, in this study, $\mathrm{BrPAH}$ emission from sources during the heating period, such as coal

Table 2

The ratios of selected chlorinated polycyclic aromatic hydrocarbon (ClPAH) normalized to 1-chloropyrene (1-CIPyr) and 3-chlorofluoranthene (3-CIFlu).

\begin{tabular}{|c|c|c|c|c|c|c|c|c|c|c|c|}
\hline & \multicolumn{6}{|l|}{ PM } & \multirow{2}{*}{$\begin{array}{l}\mathrm{PM}_{10} \text {-associated } \\
\text { Suburban air }\end{array}$} & \multirow{2}{*}{$\mathrm{PM}_{2.5}$-associated } & \multicolumn{3}{|l|}{ Gas } \\
\hline & Heating $^{\mathrm{a}}$ & Nonheating ${ }^{\mathrm{a}}$ & Road tunnel $^{\mathrm{b}}$ & Fly $\operatorname{ash}^{\mathrm{c}}$ & e-Waste dust ${ }^{\mathrm{d}}$ & Urban air ${ }^{\mathrm{e}}$ & & & Heating ${ }^{\mathrm{a}}$ & Nonheating $^{\mathrm{a}}$ & Road tunnel $^{\mathrm{b}}$ \\
\hline 6-ClBaP/1-ClPyr & 0.72 & 2.72 & 0.41 & 2.45 & 2.61 & 2.83 & 2.35 & 2.24 & 0.04 & 0.02 & \\
\hline 3-ClFlu/1-ClPyr & 1.30 & 1.06 & 0.68 & 0.65 & 0.22 & 0.60 & 0.89 & 0.87 & 2.24 & 1.55 & 0.37 \\
\hline 7-ClBaA/1-ClPyr & 0.19 & 0.61 & 0.16 & 0.63 & 1.35 & 0.60 & 0.81 & 0.55 & 0.02 & 0.07 & \\
\hline 6-ClBaP/3-ClFlu & 0.61 & 3.19 & 0.61 & 3.74 & 11.6 & 4.84 & 2.64 & 2.58 & 0.02 & 0.02 & \\
\hline 1-ClPyr/3-ClFlu & 0.92 & 1.12 & 1.47 & 1.53 & 4.46 & 1.68 & 1.13 & 1.15 & 0.54 & 0.85 & 2.74 \\
\hline 7-ClBaA/3-ClFlu & 0.17 & 0.73 & 0.23 & 0.96 & 6.04 & 1.00 & 0.91 & 0.63 & 0.01 & 0.05 & \\
\hline
\end{tabular}

a Data from this study.

b Data from Nilsson and Ostman (1993).

c Data from Horii et al. (2008).

d Data from Ma et al. (2009).

${ }^{f}$ Data from Ma et al. (2013).

e Data from Kitazawa et al. (2006). 
Table 3

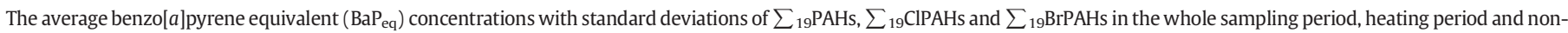
heating period. PAHs: polycyclic aromatic hydrocarbons, ClPAHs: chlorinated PAHs, BrPAHs: brominated PAHs.

\begin{tabular}{|c|c|c|c|c|c|}
\hline Sampling period & & Samples & PAHs (ng m ${ }^{-3}$ ) & ClPAHs $\left(\mathrm{pg} \mathrm{m}^{-3}\right)$ & BrPAHs $\left(\mathrm{pg} \mathrm{m}^{-3}\right)$ \\
\hline \multirow[t]{3}{*}{ Whole } & Total & 23 & $49.7 \pm 75.8$ & $33.1 \pm 55.8$ & $0.38 \pm 0.48$ \\
\hline & Gaseous phase & & $2.18 \pm 1.69$ & $4.76 \pm 3.25$ & $0.05 \pm 0.09$ \\
\hline & Particulate phase & & $47.5 \pm 74.6$ & $28.3 \pm 49.2$ & $0.33 \pm 0.47$ \\
\hline \multirow[t]{3}{*}{ Heating } & Total & 11 & $95.6 \pm 90.4$ & $58.4 \pm 65.4$ & $0.66 \pm 0.58$ \\
\hline & Gaseous phase & & $2.98 \pm 2.10$ & $4.95 \pm 4.13$ & $0.07 \pm 0.12$ \\
\hline & Particulate phase & & $92.6 \pm 89.0$ & $53.5 \pm 63.1$ & $0.59 \pm 0.57$ \\
\hline \multirow[t]{3}{*}{ Non-heating } & Total & 12 & $7.67 \pm 5.28$ & $9.84 \pm 5.95$ & $0.12 \pm 0.09$ \\
\hline & Gaseous phase & & $1.45 \pm 0.69$ & $4.59 \pm 2.35$ & $0.03 \pm 0.03$ \\
\hline & Particulate phase & & $6.22 \pm 4.83$ & $5.25 \pm 3.92$ & $0.09 \pm 0.08$ \\
\hline
\end{tabular}

burning, did not seem to sufficiently influence the BrPAH profiles in the atmosphere.

\subsection{BaP eq concentrations and daily intake of atmospheric PAHs, ClPAHs and BrPAHs}

It was reported that exposure to air pollution increases the lung cancer incidence and mortality. Around 223,000 lung cancer deaths caused by air pollution were estimated to occur in 2010 (Kurt Straif, 2013). $\mathrm{BaP}_{\text {eq }}$ concentrations of PAHs, ClPAHs and BrPAHs in air samples were calculated by multiplying the congener concentrations by their corresponding RPFs (Table 3). The average $\mathrm{BaP}_{\mathrm{eq}}$ concentrations for PAHs, ClPAHs and BrPAHs were $49.7 \pm 75.8 \mathrm{ng} \mathrm{m}^{-3}, 33.1 \pm 50.8 \mathrm{pg} \mathrm{m}^{-3}$ and $0.4 \pm 0.5 \mathrm{pg} \mathrm{m}^{-3}$ over the sampling period. In addition, the $\mathrm{BaP}_{\mathrm{eq}}$ concentrations for PAHs, ClPAHs and BrPAHs were more than five times higher during the heating period than their corresponding $\mathrm{BaP}_{\mathrm{eq}}$ concentrations during the non-heating period. Previous studies have suggested that over $60 \%$ of $\mathrm{BaP}_{\mathrm{eq}}$ concentrations are attributable to gaseous phase PAHs (Tsai et al., 2002), but in this study, $>85 \%$ of $\mathrm{BaP}_{\text {eq }}$ concentrations of PAHs, ClPAHs and BrPAHs were attributed to PM. This may be because of the occurrence of high concentrations of congeners with high RPF values in PM.

The daily intake via inhalation and dermal contact were calculated (Table S9). The intakes via inhalations of PAHs, ClPAHs and BrPAHs over the whole sampling period were 85.7-6309.9, 103.6-7696.9 and $115.9-8473.5 \mathrm{ng} \mathrm{d}^{-1}$ for children, adolescents and adults, respectively. In the heating period, inhalation of PAHs, ClPAHs and BrPAHs were $>10$ times higher than for the non-heating period. The inhalation intake of PM-associated PAHs, CIPAHs and BrPAHs together were 74.9-6012.9, 95.4-8061.8 and 99.7-8376.0 $\mathrm{ng} \mathrm{d}^{-1}$ for children, adolescents and adults, respectively, which took $>90 \%$ of the total intake through inhalation. These results indicate that PM-associated PAHs, ClPAHs and BrPAHs are important for evaluating CIPAH and BrPAH risks to humans, especially on hazy days. Exposures of PAHs, ClPAHs and BrPAHs through dermal contact over the study period were 3.9-293.0, 7.2-475.0 and 7.7-537.5 $\mathrm{ng} \mathrm{d}^{-1}$ for children, adolescent and adults, respectively. Thicker clothes during heating periods could provide a barrier to particulate and gaseous PAHs, CIPAHs and BrPAHs to the skin, while thinner clothes in warmer periods may only block PM-associated PAHs, ClPAHs and BrPAHs. As a result, exposure through dermal contact was more severe in warmer versus cooler periods. In addition, the low transdermal permeability coefficients of PM-associated compounds means that skin exposures of gas-associated PAHs, ClPAHs and BrPAHs (>80\%) have higher fractions than for the particulate phase.

The combined daily intake via inhalation and the dermal contact of atmospheric PAHs, ClPAHs and BrPAHs for children, adolescents and adults were 160.8-6467.0, 215.4-8171.1 and 233.2-8861.5 $\mathrm{ng} \mathrm{d}^{-1}$, respectively. During the heating period, the daily intakes by air inhalation and dermal contact of PAHs, CIPAHs and BrPAHs were more than seven times higher than during the non-heating period. This suggests that during periods that necessitate heating, exposure to PAHs, ClPAHs and BrPAHs was more severe. Over the sampling period, inhalation of PMassociated PAHs, ClPAHs and BrPAHs was the major exposure pathway (33.0-98.8\%), followed by inhalation of gas-associated compounds (0.5-39.2\%), dermal contact with the gaseous phase $(0.2-40.8 \%)$ and dermal contact with the particulate phase $(0.004-0.8 \%$ ) (Fig. 4, Table S10). Gas phase inhalation was widely recognized as the dominant exposure pathway to atmospheric PAHs in previous publications (Gregoris et al., 2014; Ohura et al., 2008; Park et al., 2001). In this study, particulate phase was confirmed to be the dominant exposure
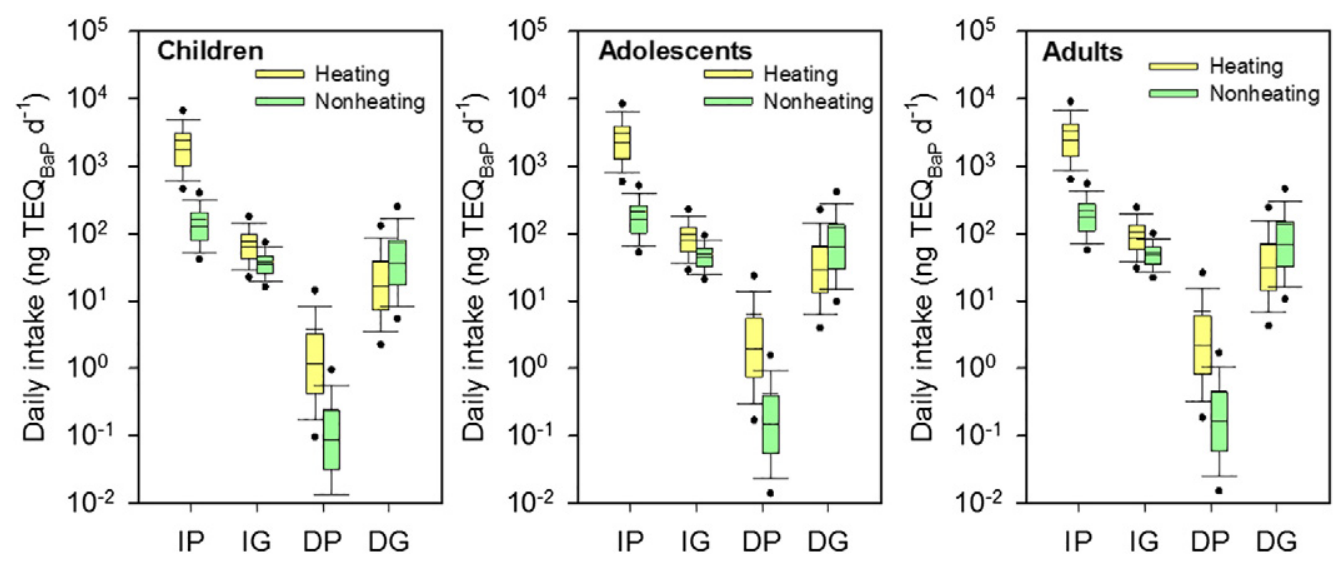

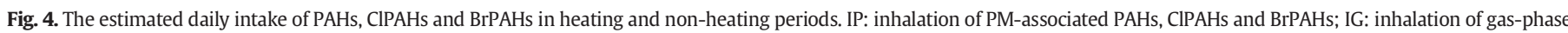
PAHs, ClPAHs and BrPAHs; DP: dermal contact of PM-associated PAHs, ClPAHs and BrPAHs; DG: dermal contact of gas-phase PAHs, ClPAHs and BrPAHs. 
pathway of atmospheric PAHs, ClPAHs and BrPAHs in haze days, which was new knowledge in the field of health risk assessment related to air pollutions.

\section{Conclusions}

In this study, air samples covering both the heating period (with more frequent haze events) and non-heating period in Beijing were collected and analysed for PAHs, ClPAHs and BrPAHs. Average concentrations of PAHs, ClPAHs and BrPAHs in heating periods were about 3-9 times of those in non-heating periods. Significant positive correlations between PAHs, ClPAHs and BrPAHs with particulate matter (PM) indicate that they share similar sources. Congener profiles indicate that secondary formation of ClPAHs is an important source, besides the primary sources. Gas phase inhalation was widely recognized as the dominant exposure pathway to atmospheric PAHs in previous publications. In this study, particulate phase was confirmed to be the dominant exposure pathway of atmospheric PAHs, ClPAHs and BrPAHs in haze days, which was new knowledge in the field of health risk assessment related to air pollutions.

\section{Acknowledgments}

This work was supported by National Natural Science Foundation of China $(91543108,21577148)$ and the Joint foundations from National Natural Science Foundation of China and United Nations Environment Programme (21361140359), State's Key Project of Research and Development Plan (2016YFC0202500), the Strategic Priority Research Program of the Chinese Academy of Sciences (XDB14020102) and the Youth Innovation Promotion Association of the Chinese Academy of Sciences (2016038).

\section{Appendix A. Supplementary data}

Supplementary data to this article can be found online at http://dx. doi.org/10.1016/j.scitotenv.2017.03.134.

\section{References}

Andersson, A., Deng, J.J., Du, K., Zheng, M., Yan, C.Q., Skold, M., et al., 2015. Regionallyvarying combustion sources of the January 2013 severe haze events over eastern China. Environ. Sci. Technol. 49, 2038-2043.

Armstrong, B.G., Gibbs, G., 2009. Exposure-response relationship between lung cance and polycyclic aromatic hydrocarbons (PAHs). Occup. Environ. Med. 66, 740-746.

Aydin, Y.M., Kara, M., Dumanoglu, Y., Odabasi, M., Elbir, T., 2014. Source apportionment of polycyclic aromatic hydrocarbons (PAHs) and polychlorinated biphenyls (PCBs) in ambient air of an industrial region in Turkey. Atmos. Environ. 97, 271-285.

Beelen, R., Hoek, G., van den Brandt, P.A., Goldbohm, R.A., Fischer, P., Schouten, L.J., et al., 2008. Long-term effects of traffic-related air pollution on mortality in a Dutch cohort (NLCS-AIR study). Environ. Health Perspect. 116, 196-202.

Betha, R., Behera, S.N., Balasubramanian, R., 2014. 2013 Southeast Asian smoke haze: frac tionation of particulate-bound elements and associated health risk. Environ. Sci. Technol. 48, 4327-4335.

Cao, C., Lee, X., Liu, S., Schultz, N., Xiao, W., Zhang, M., et al., 2016. Urban heat islands in China enhanced by haze pollution. Nat. Commun. 7, 12509.

Gao, B., Wang, X.-M., Zhao, X.-Y., Ding, X., Fu, X.-X., Zhang, Y.-L., et al., 2015. Source apportionment of atmospheric PAHs and their toxicity using PMF: impact of gas/particle partitioning. Atmos. Environ. 103, 114-120.

Gregoris, E., Argiriadis, E., Vecchiato, M., Zambon, S., De Pieri, S., Donateo, A., et al., 2014 Gas-particle distributions, sources and health effects of polycyclic aromatic hydrocarbons (PAHs), polychlorinated biphenyls (PCBs) and polychlorinated naphthalenes (PCNs) in Venice aerosols. Sci. Total Environ. 476, 393-405.

Harrison, R.M., Smith, D.J.T., Luhana, L., 1996. Source apportionment of atmospheric polycyclic aromatic hydrocarbons collected from an urban location in Birmingham, UK. Environ. Sci. Technol. 30, 825-832.

Hong, W.J., Jia, H.L., Ma, W.L., Sinha, R.K., Moon, H.B., Nakata, H., et al., 2016. Distribution, fate, inhalation exposure and lung cancer risk of atmospheric polycyclic aromatic hydrocarbons in some Asian countries. Environ. Sci. Technol. 50, 7163-7174.

Horii, Y., Khim, J.S., Higley, E.B., Giesy, J.P., Ohura, T., Kannan, K., 2009. Relative potencies of individual chlorinated and brominated polycyclic aromatic hydrocarbons for induction of aryl hydrocarbon receptor-mediated responses. Environ. Sci. Technol. 43, 2159-2165.
Horii, Y., Ok, G., Ohura, T., Kannan, K., 2008. Occurrence and profiles of chlorinated and brominated polycyclic aromatic hydrocarbons in waste incinerators. Environ. Sci. Technol. 42, 1904-1909.

Huang, R.J., Zhang, Y., Bozzetti, C., Ho, K.F., Cao, J.J., Han, Y., et al., 2014a. High secondary aerosol contribution to particulate pollution during haze events in China. Nature $514,218-222$.

Huang, R.J., Zhang, Y.L., Bozzetti, C., Ho, K.F., Cao, J.J., Han, Y.M., et al., 2014b. High secondary aerosol contribution to particulate pollution during haze events in China. Nature $514,218-222$.

International Commission on Radiological Protection, 1994. Human respiratory tract model for radiological protection. ICRP Publication 66. Annals of the ICRP 24, pp. 1-482.

Jia, Y.L., Stone, D., Wang, W.T., Schrlau, J., Tao, S., Simonich, S.L.M., 2011. Estimated reduction in cancer risk due to PAH exposures if source control measures during the 2008 Beijing Olympics were sustained. Environ. Health Perspect. 119, 815-820.

Kakimoto, K., Nagayoshi, H., Konishi, Y., Kajimura, K., Ohura, T., Hayakawa, K., et al., 2014. Atmospheric chlorinated polycyclic aromatic hydrocarbons in East Asia. Chemosphere 111, 40-46.

Kakimoto, K., Nagayoshi, H., Konishi, Y., Kajimura, K., Ohura, T., Nakano, T., et al., 2016. Size distribution of chlorinated polycyclic aromatic hydrocarbons in atmospheric particles. Arch. Environ. Contam. Toxicol.

Kitazawa, A., Amagai, T., Ohura, T., 2006. Temporal trends and relationships of particulate chlorinated polycyclic aromatic hydrocarbons and their parent compounds in urban air. Environ. Sci. Technol. 40, 4592-4598.

Kurt Straif, A.C., 2013. In: Samet, Jonathan (Ed.), Air Pollution and Cancer. International Agency for Research on Cancer, 150 cours Albert Thomas, 69372 Lyon Cedex 08, France.

Lelieveld, J., Evans, J.S., Fnais, M., Giannadaki, D., Pozzer, A., 2015. The contribution of outdoor air pollution sources to premature mortality on a global scale. Nature 525, 367-371.

Li, S.M., Liu, G.R., Zheng, M.H., Liu, W.B., Wang, M., Xiao, K., et al., 2015. Comparison of the contributions of polychlorinated dibenzo-p-dioxins and dibenzofurans and other unintentionally produced persistent organic pollutants to the total toxic equivalents in air of steel plant areas. Chemosphere 126, 73-77.

Liu, J.W., Li, J., Zhang, Y.L., Liu, D., Ding, P., Shen, C.D., et al., 2014. Source apportionment using radiocarbon and organic tracers for $\mathrm{PM}_{2.5}$ carbonaceous aerosols in Guangzhou, South China: contrasting local- and regional-scale haze events. Environ. Sci. Technol. 48, 12002-12011

Ma, J., Chen, Z.Y., Wu, M.H., Feng, J.L., Horii, Y., Ohura, T., et al., 2013. Airborne $\mathrm{PM}_{2.5} / \mathrm{PM}_{10^{-}}$ associated chlorinated polycyclic aromatic hydrocarbons and their parent compounds in a suburban area in Shanghai, China. Environ. Sci. Technol. 47, 7615-7623.

Ma, J., Horii, Y., Cheng, J., Wang, W., Wu, Q., Ohura, T., et al., 2009. Chlorinated and parent polycyclic aromatic hydrocarbons in environmental samples from an electronic waste recycling facility and a chemical industrial complex in China. Environ. Sci. Technol. 43, 643-649.

Ma, W.L., Li, Y.F., Qi, H., Sun, D.Z., Liu, L.Y., Wang, D.G., 2010. Seasonal variations of sources of polycyclic aromatic hydrocarbons (PAHs) to a northeastern urban city, China. Chemosphere $79,441-447$.

Maher, B.A., Ahmed, I.A., Karloukovski, V., MacLaren, D.A., Foulds, P.G., Allsop, D., et al., 2016. Magnetite pollution nanoparticles in the human brain. Proc. Natl. Acad. Sci. U. S. A. $113,10797-10801$.

Nilsson, U.L., Ostman, C.E., 1993. Chlorinated polycyclic aromatic hydrocarbons: method of analysis and their occurrence in urban air. Environ. Sci. Technol. 27, 1826-1831.

Noma, Y., Yamamoto, T., Sakai, S.I., 2004. Congener-specific composition of polychlorinated naphthalenes, coplanar PCBs, dibenzo-p-dioxins, and dibenzofurans in the halowax series. Environ. Sci. Technol. 38, 1675-1680.

Ohura, T., Fujima, S., Amagai, T., Shinomiya, M., 2008. Chlorinated polycyclic aromatic hydrocarbons in the atmosphere: seasonal levels, gas-particle partitioning, and origin. Environ. Sci. Technol. 42, 3296-3302.

Ohura, T., Kamiya, Y., Ikemori, F., 2016. Local and seasonal variations in concentrations of chlorinated polycyclic aromatic hydrocarbons associated with particles in a Japanese megacity. J. Hazard. Mater. 312, 254-261.

Ohura, T., Kitazawa, A., Amagai, T., Makino, M., 2005. Occurrence, profiles, and photostabilities of chlorinated polycyclic aromatic hydrocarbons associated with particulates in urban air. Environ. Sci. Technol. 39, 85-91.

Ohura, T., Morita, M., Makino, M., Amagai, T., Shimoi, K., 2007. Aryl hydrocarbon receptormediated effects of chlorinated polycyclic aromatic hydrocarbons. Chem. Res. Toxicol. 20, 1237-1241.

Ohura, T., Sawada, K.I., Amagai, T., Shinomiya, M., 2009. Discovery of novel halogenated polycyclic aromatic hydrocarbons in urban particulate matters: occurrence, photostability, and AhR activity. Environ. Sci. Technol. 43, 2269-2275.

Paloluoğlu, C., Bayraktar, H., Aktan, M., Turalioglu, F.S., Gaga, E.E., 2015. Atmospheric concentrations of polycyclic aromatic hydrocarbons (PAHs) in an urban traffic site in Erzurum, Turkey. Stoch. Env. Res. Risk A. 30, 1223-1234.

Park, J.S., Wade, T.L., Sweet, S., 2001. Atmospheric distribution of polycyclic aromatic hydrocarbons and deposition to Galveston Bay, Texas, USA. Atmos. Environ. 35, 3241-3249.

Phoothiwut, S., Junyapoon, S., 2013. Size distribution of atmospheric particulates and particulate-bound polycyclic aromatic hydrocarbons and characteristics of PAHs during haze period in Lampang Province, Northern Thailand. Air Qual. Atmos. Health 6, 397-405.

Pope, C.A., Burnett, R.T., Thun, M.J., Calle, E.E., Krewski, D., Ito, K., et al., 2002. Lung cancer, cardiopulmonary mortality, and long-term exposure to fine particulate air pollution. JAMA 287, 1132-1141.

Sangiorgi, G., Ferrero, L., Perrone, M.G., Papa, E., Bolzacchini, E., 2014. Semivolatile PAH and n-alkane gas/particle partitioning using the dual model: up-to-date coefficients and comparison with experimental data. Environ. Sci. Pollut. Res. 21, 10163-10173. 
Sun, J.-L., Jing, X., Chang, W.-J., Chen, Z.-X., Zeng, H., 2015. Cumulative health risk assessment of halogenated and parent polycyclic aromatic hydrocarbons associated with particulate matters in urban air. Ecotoxicol. Environ. Saf. 113, 31-37.

Sun, Y., Chen, C., Zhang, Y., Xu, W., Zhou, L., Cheng, X., et al., 2016. Rapid formation and evolution of an extreme haze episode in Northern China during winter 2015. Sci. Rep. 6, 27151.

Tsai, P.J., Shieh, H.Y., Lee, W.J., Lai, S.O., 2002. Characterization of PAHs in the atmosphere of carbon black manufacturing workplaces. J. Hazard. Mater. 91, 25-42.

Van den Berg, M., Birnbaum, L.S., Denison, M., De Vito, M., Farland, W., Feeley, M., et al., 2006. The 2005 World Health Organization reevaluation of human and mammalian toxic equivalency factors for dioxins and dioxin-like compounds. Toxicol. Sci. 93, 223-241.

Wang, J., Chen, S., Tian, M., Zheng, X., Gonzales, L., Ohura, T., et al., 2012. Inhalation cancer risk associated with exposure to complex polycyclic aromatic hydrocarbon mixtures in an electronic waste and urban area in South China. Environ. Sci. Technol. 46, 9745-9752.

Wang, M., Liu, G., Jiang, X., Zheng, M., Yang, L., Zhao, Y., et al., 2016. Thermochemical formation of polybrominated dibenzo- $p$-dioxins and dibenzofurans mediated by secondary copper smelter fly ash, and implications for emission reduction. Environ. Sci. Technol. 50, 7470-7479.

Wang, Y., Zhang, R., Saravanan, R., 2014. Asian pollution climatically modulates mid-latitude cyclones following hierarchical modelling and observational analysis. Nat. Commun. 5, 3098

Xia, Z., Duan, X., Tao, S., Qiu, W., Liu, D., Wang, Y., et al., 2013. Pollution level, inhalation exposure and lung cancer risk of ambient atmospheric polycyclic aromatic hydrocarbons (PAHs) in Taiyuan, China. Environ. Pollut. 173, 150-156.

Zhang, Y., Lin, Y., Cai, J., Liu, Y., Hong, L., Qin, M., et al., 2016. Atmospheric PAHs in North China: spatial distribution and sources. Sci. Total Environ. 565, 994-1000.

Zhang, Y., Tao, S., Shen, H., Ma, J., 2009. Inhalation exposure to ambient polycyclic aromatic hydrocarbons and lung cancer risk of Chinese population. Proc. Natl. Acad. Sci. U. S. A. 106, 21063-21067.

Zheng, G., Duan, F., Ma, Y., Zhang, Q., Huang, T., Kimoto, T., et al., 2016. Episode-based evolution pattern analysis of haze pollution: method development and results from Beijing, China. Environ. Sci. Technol. 50, 4632-4641. 